\title{
c-Jun N-terminal kinase-mediated anti-inflammatory effects of Garcinia subelliptica in macrophages
}

\author{
YOUNG-CHANG CHO and SAYEON CHO \\ Laboratory of Molecular and Pharmacological Cell Biology, College of Pharmacy, \\ Chung-Ang University, Seoul 156-756, Republic of Korea
}

Received February 25, 2015; Accepted December 23, 2015

DOI: $10.3892 / \mathrm{mmr} .2016 .4791$

\begin{abstract}
Garcinia plants have been traditionally used to treat inflammatory diseases, such as skin infections and pain, in many regions including South-East Asia. Garcinia subelliptica, a plant of the Garcinia species widely distributed from Japan to Thailand, has been reported to contain components similar to other Garcinia plants that exhibit anti-inflammatory effects. The present study aimed to explore the anti-inflammatory effects of ethanol extracts of Garcinia subelliptica (EGS) in macrophages, as there are no previous systemic studies that have investigated the effects of Garcinia subelliptica on inflammation. Non-cytotoxic concentrations of EGS $(\leq 200 \mu \mathrm{g} / \mathrm{ml})$ were observed to reduce nitric oxide production by modulating iNOS expression in lipopolysaccharide (LPS)-stimulated RAW 264.7 macrophages. The expression of cyclooxygenase-2, the enzyme responsible for the production of prostaglandin $\mathrm{E}_{2}$, was notably reduced by EGS. EGS treatment inhibited the production of pro-inflammatory cytokines, including IL- 6 and IL-1 $\beta$, however, not TNF- $\alpha$. Reduced production of inflammatory mediators by EGS was followed by reduced phosphorylation of c-Jun N-terminal kinase (JNK) however, not of other mitogen-activated protein kinases and nuclear factor- $\kappa \mathrm{B}$. These results indicate that EGS selectively inhibits the excessive production of inflammatory mediators in LPS-stimulated murine macrophages by reducing the activation of JNK, suggesting that EGS is a candidate for modulating severe inflammation.
\end{abstract}

\section{Introduction}

Macrophages are important cells in the immune system that act as the first defense against invading agents (bacteria, viruses, and fungi) by releasing cellular signaling molecules

Correspondence to: Professor Sayeon Cho, Laboratory of Molecular and Pharmacological Cell Biology, College of Pharmacy, Chung-Ang University, 84 Heukseok-Ro, Dongjak-Gu, Seoul 156-756, Republic of Korea

E-mail: sycho@cau.ac.kr

Key words: ethanol extracts of Garcinia subelliptica, nitric oxide, interleukin-6, tumor necrosis factor- $\alpha$, c-Jun $\mathrm{N}$-terminal kinase and antimicrobial agents (1-4). Inflammatory responses in macrophages are induced upon the stimulation of macrophages with external stimuli, such as lipopolysaccharides (LPS). Inflammatory responses include the expression of various pro-inflammatory mediators, such as nitric oxide (NO), which is produced by inducible nitric oxide synthase (iNOS), and prostaglandin $\mathrm{E}_{2}\left(\mathrm{PGE}_{2}\right)$, which is produced by cyclooxygenase (COX)-2, in addition to the expression of various pro-inflammatory cytokines, including interleukin (IL)-1 $\beta$, IL-6 and tumor necrosis factor (TNF)- $\alpha$ (5-10). Excessive amounts of these mediators cause severe inflammatory diseases, including septic shock, rheumatoid arthritis, systemic lupus erythematosus and inflammatory bowel disease, although the enhanced production of inflammatory mediators is important for the host defense against external stimuli (10-16). Therefore, inhibiting the excessive production of inflammatory mediators in macrophages by regulating mRNA and protein expression levels may be a viable strategy to develop effective anti-inflammatory agents.

A study from the World Health Organization has indicated that greater than $80 \%$ of the population in developing countries still use natural plants as their main medicinal source (17). The Garcinia species have been used traditionally for the treatment of inflammatory diseases worldwide. The ethanol and dichloromethane extracts of the fruit hull of Garcinia mangostana, a Thai traditional medicine for the treatment of abscesses and skin infections (18), have been reported to exhibit anti-inflammatory activity (19) and potent antinociceptive effects in mice (20). The ethyl acetate extract of Garcinia hanburyi, a Thai folk medicine used to treat infected wounds $(21,22)$, has been assessed for anti-inflammatory, analgesic and antipyretic activities (23). The hydroalcoholic extracts of the leaves from Garcinia gardneriana, a plant traditionally used in southern Brazil to treat skin disorders (24), have shown anti-inflammatory activity in several experimental models (25).

Polyphenols and their metabolites in Garcinia plants are known to exhibit anti-inflammatory properties. Of these polyphenols, kolaviron, a biflavonoid complex from Garcinia kola, and garcinol, a polyisoprenylated benzophenone derivative isolated from Garcinia indica, have been applied to animal models to evaluate their anti-inflammatory effects (26-29). Garcinia subelliptica (G. subelliptica) is a Garcinia species that is distributed widely from Okinawa Island in Japan to 
Thailand, and contains secondary polyphenolic metabolites which are known to exert anti-inflammatory effects (30-32). Furthermore, G. subelliptica has been reported to contain phloroglucinols and terpenoids that exhibit anti-inflammatory properties similar to those of other Garcinia plants (33). Garcinielliptones exert anti-inflammatory effects by inhibiting chemical mediators and xanthine oxidase in mast cells, neutrophils and macrophages (33-35). However, systemic studies for the anti-inflammatory effects of the ethanol extract of G. subelliptica (EGS) have not been reported.

In the present study, the anti-inflammatory effects of EGS exerted through the modulation of the production of inflammatory mediators in LPS-stimulated RAW 264.7 macrophages (ATSS, Manassas, VA, USA) were investigated to evaluate the potential of EGS for the treatment of excessive inflammation. Furthermore, the associated signaling pathways, such as the phosphorylation of the inhibitor of $\kappa \mathrm{B}(\mathrm{I} \kappa \mathrm{B})$ and the mitogen-activated protein kinase (MAPK) pathway, were investigated to assess the molecular targets of EGS.

\section{Materials and methods}

Cell culture and reagents. A 95\% ethanol extract (Code no.: FBM124-035) of the Garcinia subelliptica Merr. (Clusiaceae) was purchased from the International Biological Material Research Center (Daejeon, Korea). The RAW 264.7 macrophages, a mouse monocytic cell line, were cultured in Dulbecco's modified Eagle's medium (Invitrogen; Thermo Fisher Scientific, Inc., Waltham, MA, USA) supplemented with $10 \%$ fetal bovine serum (Invitrogen; Thermo Fisher Scientific, Inc.), 50 unit $/ \mathrm{ml}$ penicillin, and $50 \mu \mathrm{g} / \mathrm{ml}$ streptomycin (Gibco; Thermo Fisher Scientific, Inc.) at $37^{\circ} \mathrm{C}$ in humidified air containing $5 \% \mathrm{CO}_{2}$. The cytokines that were produced, including TNF- $\alpha$ and IL-6, were measured using enzyme-linked immunosorbent assay (ELISA) Ready-SET-Go! ${ }^{\circledR}$ kits (eBioscience, Inc., San Diego, CA, USA). Rabbit anti-I $\kappa \mathrm{B} \alpha$ (sc-371) and rabbit anti-glyceraldehyde 3-phosphate dehydrogenase (GAPDH; sc-25778) polyclonal antibodies were purchased from Santa Cruz Biotechnology, Inc. (Dallas, TX, USA). Mouse anti-phos-

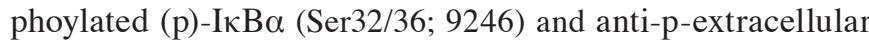
signal-regulated kinase $1 / 2$ (ERK 1/2; 9106) monoclonal antibodies; and rabbit anti-iNOS (2982), anti-COX-2 (4842), anti-p-p38 (9211), anti-p38 (9212), anti-ERK 1/2 (9102), anti-p-c-Jun N-terminal kinase (JNK; 9251) and anti-JNK (9252) polyclonal antibodies; and goat anti-rabbit horseradish peroxidase (HRP)-conjugated immunoglobulin (Ig)G (7074) and horse anti-mouse HRP-conjugated IgG (7076) were purchased from Cell Signaling Technology, Inc. (Danvers, MA, USA).

Cell viability assay. RAW 264.7 macrophages were seeded in 96 well plates (4x10/well). Following adhesion overnight, cells were incubated with 20, 50, 100, 200, and $400 \mu \mathrm{g} / \mathrm{ml}$ EGS and $1 \mu \mathrm{g} / \mathrm{ml}$ LPS for $24 \mathrm{~h}$. Following incubation, cell viability was measured using an EZ-Cytox Cell Viability Assay kit (Daeil Lab Services Co., Ltd., Seoul, Korea). Briefly, the EZ-Cytox solution that contained a water soluble tetrazolium salt was added to each well for $2 \mathrm{~h}$ at $37^{\circ} \mathrm{C}$ and $100 \mu \mathrm{l}$ of supernatants were transferred to 96 well plates. The absorbance was measured at $450 \mathrm{~nm}$ with a Synergy H1 Microplate Reader (BioTek Instruments, Inc., Winooski, VT, USA).

Nitrite assay. RAW 264.7 macrophages were incubated with 20, 50, 100 and $200 \mu \mathrm{g} / \mathrm{ml}$ EGS and $1 \mu \mathrm{g} / \mathrm{ml} \mathrm{LPS} \mathrm{for}$ $24 \mathrm{~h}$. Following incubation the levels of NO synthesis were determined by assaying the culture supernatants for nitrite using the Griess reagent ( $1 \%$ sulfanilamide, $0.1 \%$ $\mathrm{N}$-1-naphthylenediamine dihydrochloride, and $2.5 \%$ phosphoric acid). Nitrate is the stable product of the reaction between NO and molecular oxygen. The absorbance was measured at $540 \mathrm{~nm}$, using a Synergy H1 Microplate Reader, following incubation for $10 \mathrm{~min}$.

ELISA. RAW 264.7 macrophages were stimulated with $1 \mu \mathrm{g} / \mathrm{ml}$ LPS and 20, 50, 100 and $200 \mu \mathrm{g} / \mathrm{ml}$ EGS for $24 \mathrm{~h}$. Following stimulation, the supernatants were obtained via centrifugation at $2,339 \mathrm{x}$ g for $3 \mathrm{~min}$ at $4^{\circ} \mathrm{C}$, and a sandwich ELISA was performed according to the manufacturer's instructions, using monoclonal antibodies specific to each mediator to determine the quantity of TNF- $\alpha$ and IL-6 in the culture supernatants. Prior to the application of samples, the plate was pre-coated with the coating antibody in the supplied buffer. Following incubation overnight at $4^{\circ} \mathrm{C}$, the plate was washed with $1 \mathrm{X}$ phosphate-buffered saline (PBS)-Tween 20 $(0.5 \%)$ and treated with $1 \mathrm{X}$ assay diluents for $1 \mathrm{~h}$. Samples were loaded into each well and incubated for $2 \mathrm{~h}$ at room temperature. Following washing, the plate was treated with a biotinylated secondary antibody solution and HRP-streptavidin solution for $1.5 \mathrm{~h}$, and the substrate solution was added to the washed-plate. Following $10 \mathrm{~min}$ incubation in dark conditions, $1 \mathrm{~N}$ phosphoric acid $\left(\mathrm{H}_{3} \mathrm{PO}_{4}\right)$ was added and the optical density of the individual wells was measured at $450 \mathrm{~nm}$ using a Synergy Microplate Reader.

Reverse transcription-quantitative polymerase chain reaction (RT-qPCR). RAW 264.7 macrophages were stimulated with $50 \mathrm{ng} / \mathrm{ml}$ LPS and 20, 50, 100 and $200 \mu \mathrm{g} / \mathrm{ml}$ EGS for $6 \mathrm{~h}$. Total RNA was extracted from the cells via isoproponal precipitation using Accuzol reagent (Bioneer Corporation, Daejeon, Korea), reverse-transcribed into complementary DNA (cDNA) using a TOPscript ${ }^{\mathrm{TM}}$ cDNA synthesis kit (Enzynomics, Daejeon, Korea) and then PCR amplified. Quantification of mRNA was performed using a real-time PCR reagent, iTaq $^{\mathrm{TM}}$ Universal SYBR Green Supermix (Bio-Rad Laboratories, Inc., Hercules, CA, USA), according to the manufacturer's instructions. The PCR was run for 40 cycles of denaturation at $94^{\circ} \mathrm{C}(5 \mathrm{sec})$ and annealing/extension at $60^{\circ} \mathrm{C}(30 \mathrm{sec})$ using a CFX Connect ${ }^{\mathrm{TM}}$ Real-Time Thermal Cycler (Bio-Rad Laboratories, Inc.). According to the $2^{-\Delta \Delta C q}$ method (36), the results were normalized to the reference genes, $\beta$-actin and GAPDH, and were expressed as the ratio of gene expressions to the LPS treated group (100\%). PCR primers were designed using Beacon Designer 7.0 (Premier Biosoft, Palo Alto, CA, USA) and subsequently synthesized by Bioneer Corporation. The sequences of PCR primers used are as follows: Mouse iNOS, sense 5'-TGG CCACCAAGCTGAACT-3' and antisense 5'-TCATGA TAACGT TTCTGGCTCTT-3'; COX-2, sense 5'-GAT GCTCTTCCGAGCTGTG-3' and antisense 5'-GGATTG 
GAACAGCAAGGATTT-3'; TNF- $\alpha$, sense 5'-CTGTAG CCCACGTCGTAGC-3' and antisense 5'-TTGAGATCC ATGCCGTTG-3'; IL-6, sense 5'-TCTAATTCATATCTT CAACCAAGAGG-3' and antisense 5'-TGGTCCTTAGCC ACTCCTTC-3'; IL-1 $\beta$, sense 5'-TTGACGGACCCCAAA AGAT-3' and antisense 5'-GATGTGCTGCTGCGAGATT-3'; $\beta$-actin, sense 5'-CGTCATACTCCTGCTTGCTG-3' and antisense 5'-CCAGATCATTGCTCCTCCTGA-3'; and GAPDH, sense 5'-GCTCTCTGCTCCTCCTGTTC-3' and antisense 5'-ACGACCAAATCCGTTGACTC-3'.

Semi-quantitative RT-PCR. PCR primers were designed using Primer3 software (version 4.0.0), as previously described (37), and were subsequently synthesized by Bioneer Corporation. The sequences of the PCR primers used study are as follow: Mouse iNOS, sense 5'-GCATGG AACAGTATAAGGCAAACA-3' and antisense 5'-GTTTCT GGTCGATGTCATGAGCAA-3'; COX-2, sense 5'-GCATGG AACAGTATAAGGCAAACA-3' and antisense 5'-GTTTCT GGTCGATGTCATGAGCAA-3'; TNF- $\alpha$, sense 5'-GTGCCA GCCGATGGGTTGTACC-3' and antisense 5-'AGGCCC ACAGTCCAGGTCACTG-3'; IL-6, sense 5'-TCTTGGGAC TGATGCTGGTGAC-3' and antisense 5'-CATAACGCA CTAGGTTTGCCGA-3'; IL-1 $\beta$, sense 5'-AGCTGTGGCAGC TACCTGTG-3' and antisense 5'-GCTCTGCTTGTGAGG TGCTG-3'; and GAPDH, sense 5'-GTCTTCACCACCATG GAGAAGG-3' and antisense 5'-CCTGCTTCACCACCT TCTTGCC-3'. The PCR was run for $20-25$ cycles of $94^{\circ} \mathrm{C}$ $(30 \mathrm{sec}), 60^{\circ} \mathrm{C}(30 \mathrm{sec})$, and $72^{\circ} \mathrm{C}(30 \mathrm{sec})$ using a Genetouch thermal cycler (Bioer Technology Co., Ltd., Hangzhou, China). Following amplification, $10 \mu \mathrm{l}$ of the RT-PCR products were separated in $1.5 \%(\mathrm{w} / \mathrm{v})$ agarose gels and stained with ethidium bromide.

Preparation of total cell lysates. LPS-stimulated RAW 264.7 cells were treated with EGS and $1 \mu \mathrm{g} / \mathrm{ml}$ LPS for $15 \mathrm{~min}$ and washed with ice-cold PBS. The cells were lysed in lysis buffer containing $0.5 \%$ NP-40, $0.5 \%$ Triton X-100, $150 \mathrm{mM}$ $\mathrm{NaCl}, 20 \mathrm{mM}$ Tris- $\mathrm{HCl}(\mathrm{pH}$ 8.0), $1 \mathrm{mM}$ ethylenediaminetetraacetic acid, $1 \%$ glycerol, $1 \mathrm{mM}$ phenylmethylsulfonyl fluoride and $1 \mu \mathrm{g} / \mathrm{ml}$ aprotinin, and collected in microtubes prior to centrifugation at $15,814 \mathrm{x}$ g for $30 \mathrm{~min}$ at $4^{\circ} \mathrm{C}$. The supernatants were prepared in fresh microtubes.

Immunoblot analysis. Protein concentration was measured using the Bradford method (Bio-Rad Laboratories, Inc.). Aliquots $(20 \mu \mathrm{g})$ of the cell lysates were separated by $10 \%$ sodium dodecyl sulfate-polyacrylamide gel in a Mini-Protein II gel apparatus (both Bio-Rad Laboratories, Inc.) and transferred onto nitrocellulose membranes (GE Healthcare Life Sciences, Pittsburgh, WI, USA) with transfer buffer [192 mM glycine, $25 \mathrm{mM}$ Tris- $\mathrm{HCl}(\mathrm{pH} 8.8)$, and $20 \% \mathrm{MeOH}(\mathrm{v} / \mathrm{v})]$. Following blocking of non-specific sites with 5\% bovine serum albumin solution, the membrane was incubated overnight at $4^{\circ} \mathrm{C}$ with the primary antibodies (all 1:1,000). Subsequently, each membrane was incubated for $1 \mathrm{~h}$ at room temperature with secondary HRP-conjugated goat anti-rabbit or horse anti-mouse $\operatorname{IgG}(1: 5,000)$. The target proteins were detected using an enhanced chemiluminescence solution (Daeil Lab Services Co., Ltd.). Protein levels were quantified

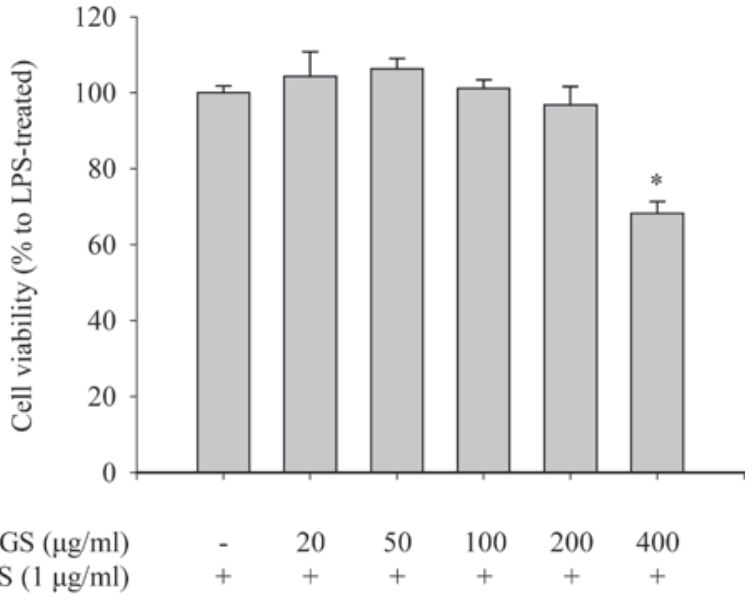

Figure 1. Effects of EGS on cell viability. RAW 264.7 macrophages were treated simultaneously with LPS $(1 \mu \mathrm{g} / \mathrm{ml})$ and EGS $(20,50,100,200$, and $400 \mu \mathrm{g} / \mathrm{ml}$ ). Following incubation for $24 \mathrm{~h}$, cell viability was measured using the EZ-Cytox reagent. Cell viability was compared with that of the LPS-treated group. Data are presented as the mean \pm standard error. ${ }^{*} \mathrm{P}<0.01$ vs. the LPS-treated control group. EGS, ethanol extracts of Garcinia subelliptica; LPS, lipopolysaccharide.

by scanning the immunoblots and analyzing them with LabWorks software (version 4.6; UVP, Inc., Upland, CA, USA).

Statistical analysis and experimental replicates. Data are presented as the mean \pm standard error of the mean. Statistical differences between each result were assessed by comparing with the LPS-treated group using the Mann-Whitney U test. Mann-Whitney U test was performed using Prism 3.0 (GraphPad Software, Inc., San Diego, CA, USA) and P<0.01 was considered to indicate a statistically significant difference. The data from nine replicates were analyzed, including three independent experiments with three replicates in each.

\section{Results}

Determination of the non-cytotoxic concentration of EGS in macrophages. Selective regulation of inflammatory mediators and the identification of specific target signaling molecules are valuable strategies for the development of novel anti-inflammatory reagents. Based on this concept, the current study investigated a number of natural plant extracts, which are known traditionally to have pharmacological effects, and evaluated their inhibitory effects on inflammation by measuring the production of $\mathrm{NO}$, a major inflammatory mediator, in LPS-stimulated RAW 264.7 macrophages. Of the extracts that exerted an inhibitory effect on NO production, EGS was selected as Garcinia species have been used traditionally to treat numerous inflammatory diseases. Considering that the anti-inflammatory effects of EGS should be studied at concentrations that do not influence cell viability, the non-cytotoxic and maximally effective concentrations of EGS were identified by the dose-dependent treatment of LPS-stimulated RAW 264.7 macrophages. Cell viability was determined by measuring the ability of cells to metabolically reduce a water-soluble tetrazolium salt to a formazan dye. As shown in Fig. 1, the cell viability of the 
A

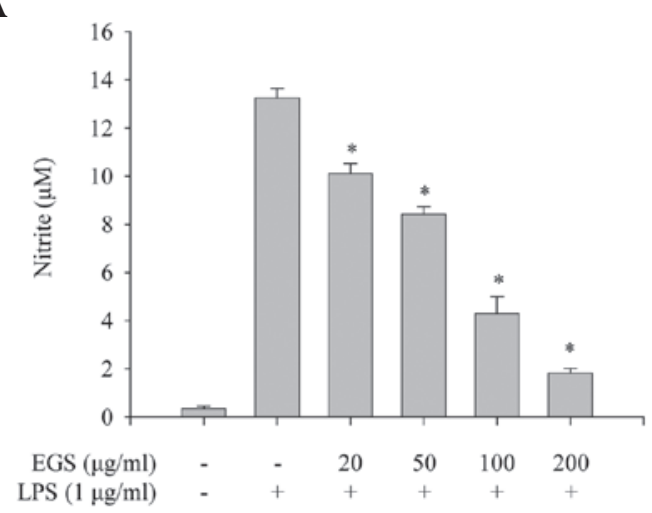

C

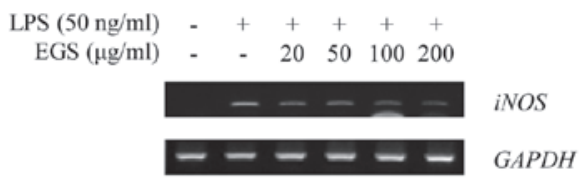

B

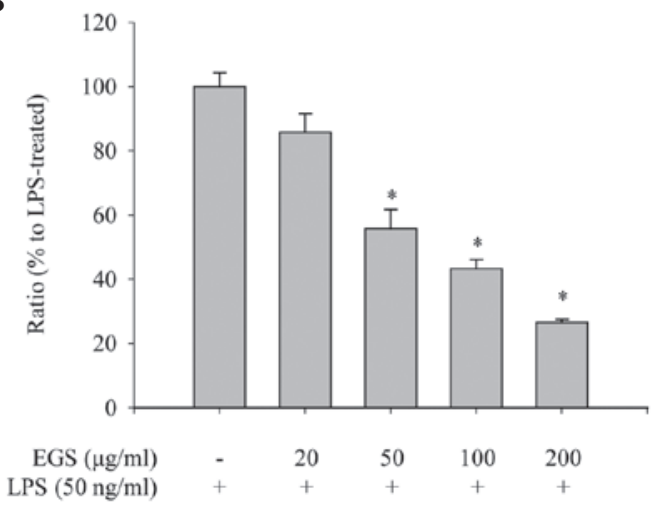

D

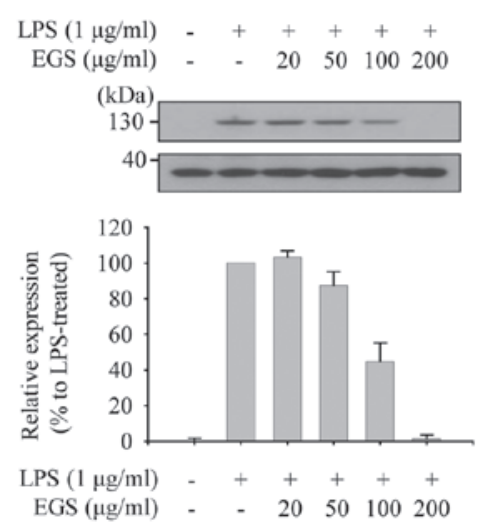

Figure 2. Inhibitory effects of EGS on the production of NO.RAW 264.7 macrophages were treated simultaneously with LPS and EGS (20,50, 100 and $200 \mu \mathrm{g} / \mathrm{ml})$ for the indicated times. (A) Following $24 \mathrm{~h}$ stimulation, NO secretion in the supernatants was measured using the Griess reagent. NO secretion was calculated using a standard curve according to a nitrite standard solution. (B) Following a $6 \mathrm{~h}$ stimulation, total RNA was extracted and reverse transcribed to cDNA $i N O S$ was amplified by reverse transcription-quantitative PCR, and the expression of $i N O S$ in each group was compared with the LPS-treated group. (C) iNOS was amplified by PCR and detected using a gel documentation system. GAPDH served as an internal control. (D) Total cell lysates were prepared following $24 \mathrm{~h}$ stimulation and subjected to immunoblot analyses. The iNOS protein expression was detected using an enhanced chemiluminescence reagent. Expression levels were quantified by analysis with LabWorks software and normalized to the corresponding GAPDH levels, and are presented as relative expression levels. Data are presented as the mean \pm standard error. "P<0.01 vs. the LPS-treated control group. EGS, ethanol extracts of Garcinia subelliptica; NO, nitric oxide; LPS, lipopolysaccharide; iNOS, inducible nitric oxide synthase; PCR, polymerase chain reaction; GAPDH, glyceraldehyde-3-phosphate dehydrogenase.

RAW 264.7 macrophages was not reduced by EGS treatment at doses of $\leq 200 \mu \mathrm{g} / \mathrm{ml}$ in the presence of $1 \mu \mathrm{g} / \mathrm{ml}$ LPS. However, a number of dead cells $(31.79 \pm 3.14 \%)$ were detected when the cells were treated with $400 \mu \mathrm{g} / \mathrm{ml}$ EGS. These results suggest that a low dose of EGS $(200 \mu \mathrm{g} / \mathrm{ml})$ does not affect the viability of RAW 264.7 macrophages. Therefore, concentrations below $200 \mu \mathrm{g} / \mathrm{ml}$ were used in subsequent experiments.

Inhibitory effect of EGS on the production of NO in $L P S$-stimulated macrophages. To evaluate the anti-inflammatory function of EGS in macrophages, the profile of NO production was measured. As expected, RAW 264.7 macrophages stimulated with LPS $(1 \mu \mathrm{g} / \mathrm{ml})$ produced a large quantity of NO compared with the non-treated control group. When the cells were treated with EGS, the enhanced production of NO by LPS was inhibited in a dose-dependent manner, and the LPS-induced NO production was nearly abolished at a dose of $200 \mu \mathrm{g} / \mathrm{ml}$ (Fig. 2A). Considering that NO production is tightly regulated by iNOS expression, the effects of EGS on the expression of iNOS mRNA and protein were investigated using PCR and immunoblot analysis. The RT-qPCR results revealed that LPS notably induces $i N O S$ expression, which was inhibited by EGS in a dose-dependent manner (Fig. 2B). Semi-quantitative PCR data indicated a similar profile of expression as the RT-qPCR data, which supported the inhibitory effect of EGS on the expression of iNOS mRNA (Fig. 2C). In addition, LPS-induced expression of iNOS protein was notably reduced by EGS in a dose-dependent manner, and the maximum dose of EGS resulted in a similar iNOS expression profile as the non-treated control group (Fig. 2D). These results imply that EGS inhibits NO production in activated macrophages by modulating iNOS expression.

Inhibitory effect of EGS on the expression of COX-2 in LPS-stimulated macrophages. As COX-2 is the enzyme responsible for the production of $\mathrm{PGE}_{2}$ in activated macrophages, the present study explored the effect of EGS on the expression levels of COX-2 mRNA and protein to measure its anti-inflammatory function. As shown in Fig. 3A, induction of $C O X-2$ mRNA expression by LPS was detected by RT-qPCR analysis. EGS treatment notably inhibited the enhanced expression of $C O X-2$ mRNA at concentrations of 100 and $200 \mu \mathrm{g} / \mathrm{ml}$. Furthermore, the inhibitory effect of EGS on the COX-2 mRNA expression detected by RT-qPCR was 
A

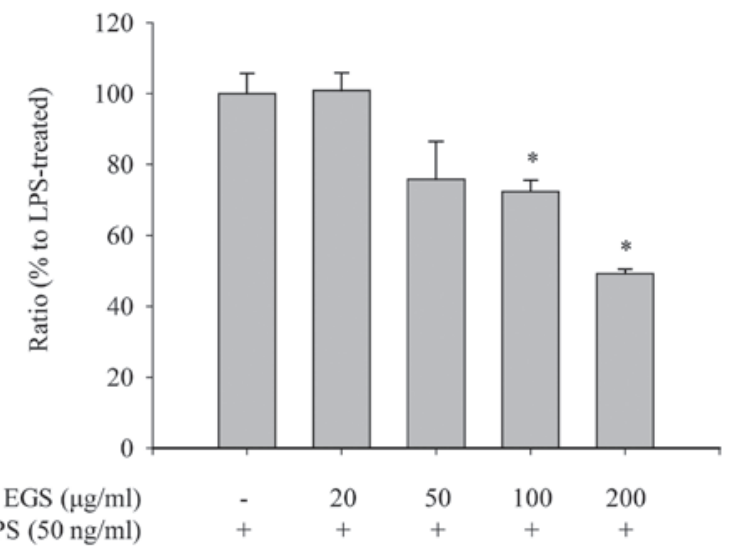

B

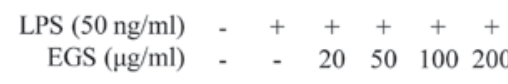

$-\cdots \operatorname{COX}-2$

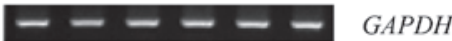

C
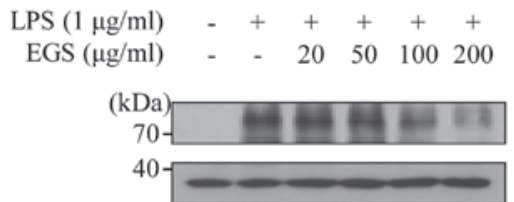

COX-2

GAPDH

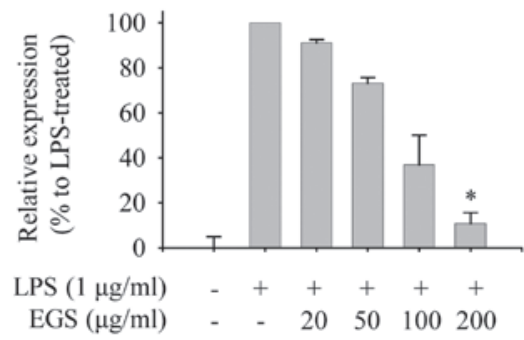

Figure 3. Effects of EGS on the expression of COX-2.RAW 264.7 macrophages were treated simultaneously with LPS and EGS $(20,50,100$ and $200 \mu \mathrm{g} / \mathrm{ml})$ for the indicated times. (A and B) Following $6 \mathrm{~h}$ stimulation, total RNA was extracted and reverse transcribed to cDNA. (A) $C O X-2$ was amplified by reverse transcription-quantitative $\mathrm{PCR}$, and the expression of $C O X-2$ in each group was compared with the LPS-treated group. (B) $C O X-2$ was amplified by PCR and detected using a gel documentation system. GAPDH expression served as an internal control. (C) Total cell lysates were prepared following $24 \mathrm{~h}$ stimulation and subjected to immunoblot analyses. The COX-2 protein expression was detected using an enhanced chemiluminescence reagent, and expression levels were normalized to levels of the GAPDH loading control, and are presented as relative expression levels. Data are presented as the mean \pm standard error. ${ }^{*} \mathrm{P}<0.01$ vs. the LPS-treated control group. EGS, ethanol extracts of Garcinia subelliptica; COX-2, cyclooxygenase 2; LPS, lipopolysaccharide; PCR, polymerase chain reaction; GAPDH, glyceraldehyde-3-phosphate dehydrogenase.

supported by semi-quantitative PCR (Fig. 3B). To examine the effect of EGS on the expression of COX-2 protein in activated macrophages, RAW 264.7 macrophages were treated with EGS in the presence of LPS, and total cell lysates were prepared. The increased levels of COX-2 protein expression mediated by LPS were reduced markedly by EGS in a dose-dependent manner (Fig. 3C). From these data, COX-2 expression was observed to be downregulated by EGS, and the subsequent production of $\mathrm{PGE}_{2}$ may therefore be regulated by EGS.

Differential regulation of inflammatory cytokine production by EGS in LPS-stimulated macrophages. To assess the anti-inflammatory properties of EGS in activated macrophages, the effects of EGS on the production of pro-inflammatory cytokines, including IL- $1 \beta$, IL- 6 and TNF- $\alpha$, were measured in LPS-stimulated RAW 264.7 macrophages. Production of IL-6 and TNF- $\alpha$ was increased notably following LPS stimulation (Fig. 4A and B). However, EGS treatment inhibited the production of IL- 6 whilst not altering the expression of TNF- $\alpha$ (Fig. 4A and B). The mRNA expression of pro-inflammatory cytokines was assessed to determine whether the production of pro-inflammatory cytokines is regulated at the transcriptional level. As presented in Fig. 4C, RT-qPCR analysis indicated that EGS treatment inhibited the LPS-stimulated expression of $I L-6$ and $I L-1 \beta$ but not $T N F-\alpha$. Similarly, semi-quantitative PCR analysis showed that EGS selectively reduced the mRNA expression levels of $I L-6$ and $I L-1 \beta$ (Fig. 4D). Taken together, these results suggest that EGS negatively regulates the LPS-induced production of pro-inflammatory cytokines by transcriptional repression of $I L-6$ and $I L-1 \beta$ however, not of $T N F-\alpha$.

Inhibitory effect of EGS on the activation of JNK in LPS-stimulated macrophages. The phosphorylation levels of $\mathrm{JNK}$ and I $\mathrm{KB}$ were measured to investigate which inflammatory signaling pathways are associated with the inhibitory effects of EGS in LPS-stimulated macrophages. As shown in Fig. 5A, LPS treatment altered the expression of $\mathrm{p}-\mathrm{I} \kappa \mathrm{B} \alpha$ and $\mathrm{I} \kappa \mathrm{B} \alpha$. However, EGS did not affect the expression profiles of p-I $\mathrm{B} \alpha$ and IкB $\alpha$. In addition, the modulation of JNK phosphorylation by EGS was measured. Immunoblot analyses revealed that EGS inhibited the phosphorylation of JNK without affecting the protein levels of JNK. EGS did not influence the phosphorylation or protein expression of additional MAPK pathway mediators, including ERK and p38. Collectively, these results suggest that EGS exerts anti-inflammatory effects by inhibiting the activation of JNK.

\section{Discussion}

In the present study, EGS was observed to markedly inhibit the production of IL- 6 and IL-1 $\beta$, however, not TNF- $\alpha$, in LPS-stimulated RAW 264.7 macrophages. Numerous reports have indicated that interleukins and TNF- $\alpha$ are not simultaneously inhibited by natural compounds $(38,39)$. One possibility for the differential regulation of pro-inflammatory cytokines by EGS is that they possess different promoter binding regions for transcription factors. Previous studies have demonstrated that the signal transducer and activator of transcription (STAT) protein-binding region is contained in the IL-6 and IL-1 $\beta$ promoter regions, however, not in the TNF- $\alpha$ promoter region (40). This implies that the specific regulation of IL-6 and IL- $1 \beta$ production by EGS in macrophages may be regulated through the inactivation of STAT signaling.

In the present study, LPS treatment of murine macrophages significantly enhanced the production of inflammatory 
A

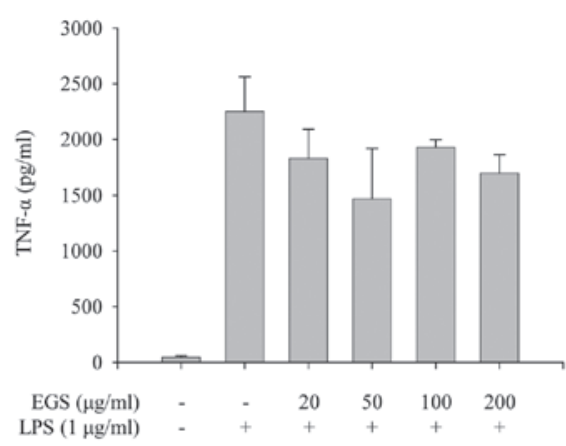

C

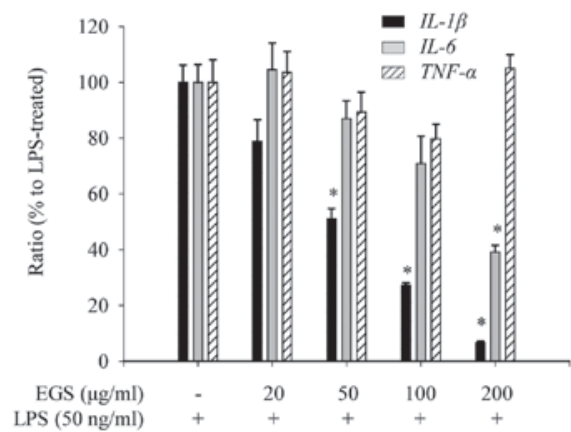

B

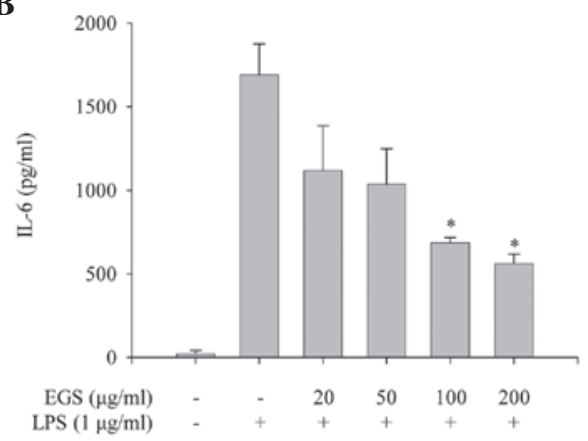

D

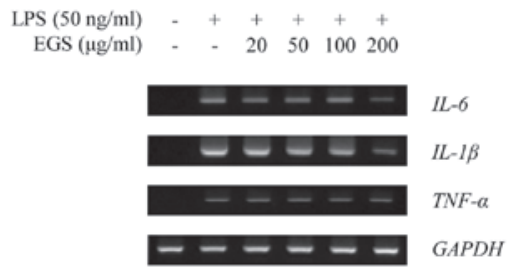

Figure 4. Inhibitory effects of EGS on the production of pro-inflammatory cytokines. RAW 264.7 macrophages were treated simultaneously with LPS and EGS $(20,50,100$ and $200 \mu \mathrm{g} / \mathrm{ml})$ for the indicated times. Following $24 \mathrm{~h}$ stimulation, enzyme-linked immunosorbent assays were used to measure the levels of (A) TNF- $\alpha$ and (B) IL-6. The secretion of each cytokine was determined using a standard curve. (C) Following a $6 \mathrm{~h}$ stimulation, total RNA was extracted and reverse transcribed to cDNA. $I L-1 \beta, T N F-\alpha$ and, $I L-6$ were amplified by reverse transcription-quantitative PCR, and the expression levels of $I L-1 \beta, T N F-\alpha$ and $I L-6$ in each group were compared with those of the LPS-treated group. (D) $I L-1 \beta, T N F-\alpha$ and, $I L-6$ were amplified by PCR and detected using a gel documentation system. GAPDH was used as a loading control. Data are presented as the mean \pm standard error. ${ }^{*} \mathrm{P}<0.01$ vs. the LPS-treated control group. EGS, ethanol extracts of Garcinia subelliptica; LPS, lipopolysaccharide; TNF- $\alpha$, tumor necrosis factor $\alpha$; IL, interleukin; PCR, polymerase chain reaction; GAPDH, glyceraldehyde-3-phosphate dehydrogenase.

A
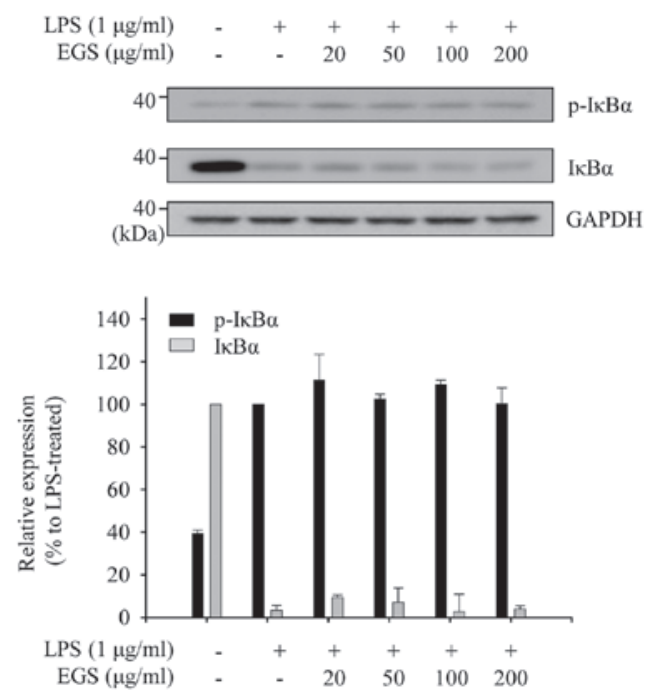

B

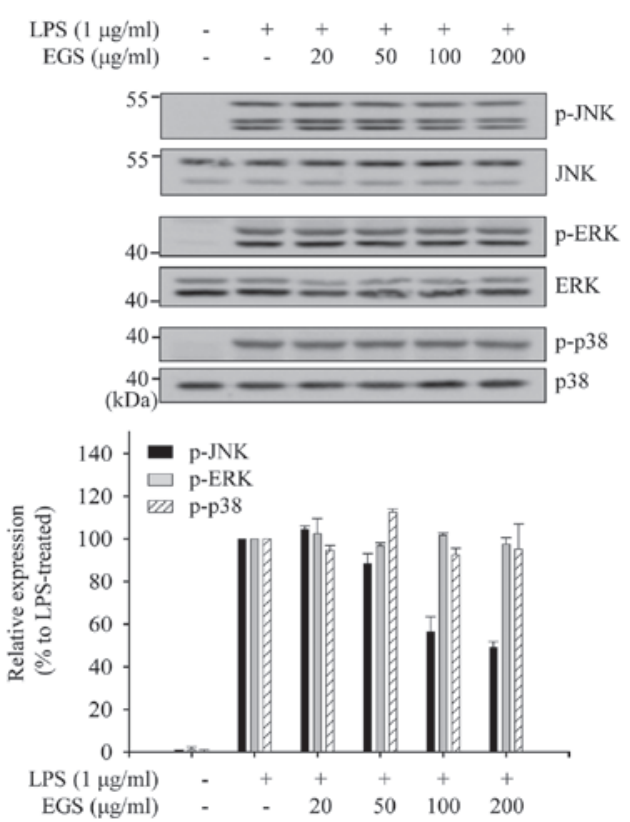

Figure 5. Inhibitory effects of EGS on NF- $\mathrm{kB}$ and MAPK activation. RAW 264.7 macrophages were pretreated with various concentrations of EGS (20, 50, 100 and $200 \mu \mathrm{g} / \mathrm{ml}$ ) for $1 \mathrm{~h}$ and then stimulated with LPS for $15 \mathrm{~min}$. Total cell lysates were prepared and subjected to immunoblot analyses. The expression

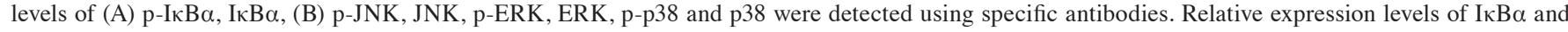
$\mathrm{p}-\mathrm{I} \kappa \mathrm{B} \alpha$ were normalized to GAPDH levels. Levels of p-JNK and p-ERK were normalized to the JNK and ERK levels, respectively. Quantitative analyses of phosphorylation and protein levels are shown following normalization (lower panel). Data are presented as the mean \pm standard error. EGS, ethanol extracts

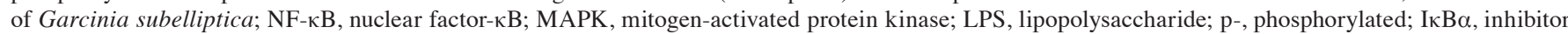
of $\kappa \mathrm{B}$ protein; JNK, c-Jun N-terminal kinase; ERK, extracellular signal-regulated kinase TNF- $\alpha$, tumor necrosis factor $\alpha$; IL, interleukin; PCR, polymerase chain reaction; GAPDH, glyceraldehyde-3-phosphate dehydrogenase. 
mediators via the stimulation of the MAPK pathway; thus, the inhibition of p38, ERK and JNK phosphorylation may represent potential target pathways for the alleviation of severe inflammatory states $(2,8,41)$. However, numerous reports have suggested that MAPK signaling cascades are differentially involved in the production of inflammatory mediators by macrophages (42-44). Watters et al (45) suggested that the MAPK/ERK pathway is not essential for the production of iNOS and IL-1 $\beta$ in macrophages. Caivano (46) and Paul et al (47) reported that the p38 and MAPK/ERK pathways are not essential for the production of inflammatory mediators. In the present study, EGS inhibited the LPS-induced phosphorylation of JNK, however, the total MAPK levels, including p38, ERK and JNK, were unaltered. Collectively, these results suggest that the regulation of JNK activity, rather than total JNK expression, is the key regulatory mechanism of EGS-mediated inhibition of inflammatory mediators.

Considering that macrophages serve pivotal roles in the pathogenesis of many inflammatory diseases, the EGS-mediated selective regulation of inflammatory mediators suggests that EGS may have therapeutic potential against inflammatory diseases. However, further studies are required to analyze the major components of EGS that are responsible for the reduction of inflammatory mediators and to elucidate the exact mechanism underlying the differences in the production of the pro-inflammatory cytokines, IL-6 and TNF- $\alpha$.

\section{Acknowledgements}

The current study was supported by a Chung-Ang University Research Grant in 2014 and a National Research Foundation of Korea (NRF) grant funded by the Ministry of Education, Science and Technology (grant no. NRF-2013R1A1A2062389).

\section{References}

1. Boscá L, Zeini M, Través PG and Hortelano S: Nitric oxide and cell viability in inflammatory cells: A role for $\mathrm{NO}$ in macrophage function and fate. Toxicology 208: 249-258, 2005.

2. Fujihara M, Muroi M, Tanamoto K, Suzuki T, Azuma H and Ikeda $\mathrm{H}$ : Molecular mechanisms of macrophage activation and deactivation by lipopolysaccharide: Roles of the receptor complex. Pharmacol Ther 100: 171-194, 2003.

3. Fujiwara $\mathrm{N}$ and Kobayashi K: Macrophages in inflammation. Curr Drug Targets Inflamm Allergy 4: 281-286, 2005.

4. MacMicking J, Xie QW and Nathan C: Nitric oxide and macrophage function. Annu Rev Immunol 15: 323-350, 1997.

5. Jones BW, Heldwein KA, Means TK, Saukkonen JJ and Fenton MJ: Differential roles of toll-like receptors in the elicitation of proinflammatory responses by macrophages. Ann Rheum Dis 60 (Suppl 3): iii6-iii12, 2001.

6. Jones BW, Means TK, Heldwein KA, Keen MA, Hill PJ, Belisle JT and Fenton MJ: Different toll-like receptor agonists induce distinct macrophage responses. J Leukoc Biol 69 1036-1044, 2001.

7. Rhee SH and Hwang D: Murine TOLL-like receptor 4 confers lipopolysaccharide responsiveness as determined by activation of NF kappa B and expression of the inducible cyclooxygenase. J Biol Chem 275: 34035-34040, 2000.

8. Schroder K, Sweet MJ and Hume DA: Signal integration between IFNgamma and TLR signalling pathways in macrophages. Immunobiology 211: 511-524, 2006.

9. Stalińska K, Guzdek A, Rokicki M and Koj A: Transcription factors as targets of the anti-inflammatory treatment. A cell culture study with extracts from some mediterranean diet plants. J Physiol Pharmacol 56 (Suppl 1): S157-S169, 2005 .
10. Szabó C and Thiemermann C: Regulation of the expression of the inducible isoform of nitric oxide synthase. Adv Pharmacol 34: 113-153, 1995.

11. Clancy RM, Amin AR and Abramson SB: The role of nitric oxide in inflammation and immunity. Arthritis Rheumatol 41: 1141-1151, 1998.

12. Guadagni F, Ferroni P, Palmirotta R, Portarena I, Formica V and Roselli M: Review. TNF/VEGF cross-talk in chronic inflammation-related cancer initiation and progression: An early target in anticancer therapeutic strategy. In Vivo 21: 147-161, 2007.

13. Kröncke KD, Fehsel K and Kolb-Bachofen V: Inducible nitric oxide synthase in human diseases. Clin Exp Immunol 113: 147-156, 1998.

14. Nathan C and Xie QW: Nitric oxide synthases: Roles, tolls and controls. Cell 78: 915-918, 1994.

15. Nathan $\mathrm{C}$ and Xie QW: Regulation of biosynthesis of nitric oxide. J Biol Chem 269: 13725-13728, 1994.

16. Nishimoto $\mathrm{N}$ and Kishimoto $\mathrm{T}$ : Interleukin 6: From bench to bedside. Nat Clin Pract Rheumatol 2: 619-626, 2006.

17. Calixto JB: Efficacy, safety, quality control, marketing and regulatory guidelines for herbal medicines (phytotherapeutic agents) Braz J Med Biol Res 33: 179-189, 2000.

18. Wutthithamavet W: Thai traditional medicine, revised edition. Odean Store Press, Bangkok, 1997.

19. Tewtrakul S, Wattanapiromsakul C and Mahabusarakam W: Effects of compounds from Garcinia mangostana on inflammatory mediators in RAW264.7 macrophage cells. J Ethnopharmacol 121: 379-382, 2009.

20. Cui J, Hu W, Cai Z, Liu Y, Li S, Tao W and Xiang H: New medicinal properties of mangostins: Analgesic activity and pharmacological characterization of active ingredients from the fruit hull of Garcinia mangostana L. Pharmacol Biochem Behav 95: 166-172, 2010.

21. Duke JA: Handbook of medical herbs. Library of congress, New York, 1985.

22. Evan WC: Trease and Evans pharmacognosy. Saunders Company Limited, Nottingham, 1996.

23. Panthong A, Norkaew P, Kanjanapothi D, Taesotikul T, Anantachoke N and Reutrakul V: Anti-inflammatory, analgesic and antipyretic activities of the extract of gamboge from Garcinia hanburyi Hookf. J Ethnopharmacol 111: 335-340, 2007.

24. Guimarães CL, Otuki MF, Beirith A and Cabrini DA: A review on the therapeutic potential of Garcinia gardneriana. Dynamis 12: 6-12, 2004 (In Portuguese).

25. Castardo JC, Prudente AS, Ferreira J, Guimarães CL, Monache FD, Filho VC, Otuki MF and Cabrini DA: Anti-inflammatory effects of hydroalcoholic extract and two biflavonoids from Garcinia gardneriana leaves in mouse paw oedema. J Ethnopharmacol 118: 405-411, 2008.

26. Ayepola OR, Chegou NN, Brooks NL and Oguntibeju OO: Kolaviron, a Garcinia biflavonoid complex ameliorates hyperglycemia-mediated hepatic injury in rats via suppression of inflammatory responses. BMC Complement Altern Med 13: 363 , 2013.

27. Farombi EO, Adedara IA, Ajayi BO, Ayepola OR and Egbeme EE: Kolaviron, a natural antioxidant and anti-inflammatory phytochemical prevents dextran sulphate sodium-induced colitis in rats. Basic Clin Pharmacol Toxicol 113: 49-55, 2013.

28. Li F, Shanmugam MK, Chen L, Chatterjee S, Basha J, Kumar AP, Kundu TK and Sethi G: Garcinol, a polyisoprenylated benzophenone modulates multiple proinflammatory signaling cascades leading to the suppression of growth and survival of head and neck carcinoma. Cancer Prev Res (Phila) 6: 843-854, 2013.

29. Tsai ML, Chiou YS, Chiou LY, Ho CT and Pan MH: Garcinol suppresses inflammation-associated colon carcinogenesis in mice. Mol Nutr Food Res 58: 1820-1829, 2014.

30. Minami H, Takahashi E, Fukuyama Y, Kodama M, Yoshizawa T and Nakagawa K: Novel xanthones with superoxide scavenging activity from Garcinia subelliptica. Chem Pharm Bull (Tokyo) 43: 347-349, 1995.

31. Minami H, Hamaguchi K, Kubo M and Fukuyama Y: A benzophenone and a xanthone from Garcinia subelliptica. Phytochemistry 49: 1783-1785, 1998.

32. Ito $T$, Yokota R, Watarai T, Mori K, Oyama M, Nagasawa $H$, Matsuda $\mathrm{H}$ and Iinuma $\mathrm{M}$ : Isolation of six isoprenylated biflavonoids from the leaves of Garcinia subelliptica. Chem Pharm Bull (Tokyo) 61: 551-558, 2013.

33. Weng JR, TsaoLT, Wang JP, Wu RR and Lin CN: Anti-inflammatory phloroglucinols and terpenoids from Garcinia subelliptica. J Nat Prod 67: 1796-1799, 2004. 
34. Weng JR, Lin CN, Tsao LT and Wang JP: Terpenoids with a new skeleton and novel triterpenoids with anti-inflammatory effects from Garcinia subelliptica. Chemistry 9: 5520-5527, 2003.

35. Weng JR, Lin CN, Tsao LT and Wang JP: Novel and anti-inflammatory constituents of Garcinia subelliptica. Chemistry 9: 1958-1963, 2003

36. Livak KJ and Schmittgen TD: Analysis of relative gene expression data using real-time quantitative PCR and the $2^{-\Delta \Delta C t}$ method. Methods 25: 402-408, 2001.

37. Koressaar T and Remm M: Enhancements and modifications of primer design program Primer3 Bioinformatics 23: 1289-91, 2007.

38. Samavati L, Rastogi R, Du W, Hüttemann M, Fite A and Franchi L: STAT3 tyrosine phosphorylation is critical for interleukin 1 beta and interleukin- 6 production in response to lipopolysaccharide and live bacteria. Mol Immunol 46: 1867-1877, 2009.

39. Zhu ZG, Jin H, Yu PJ, Tian YX, Zhang JJ and Wu SG: Mollugin Inhibits the inflammatory response in lipopolysaccharide-stimulated RAW264.7 macrophages by blocking the Janus kinase-signal transducers and activators of transcription signaling pathway. Biol Pharm Bull 36: 399-406, 2013.

40. Lee C, Lim HK, Sakong J, Lee YS, Kim JR and Baek SH: Janus kinase-signal transducer and activator of transcription mediates phosphatidic acid-induced interleukin (IL)-1beta and IL-6 production. Mol Pharmacol 69: 1041-1047, 2006.

41. Cario E, Rosenberg IM, Brandwein SL, Beck PL, Reinecker HC and Podolsky DK: Lipopolysaccharide activates distinct signaling pathways in intestinal epithelial cell lines expressing toll-like receptors. J Immunol 164: 966-972, 2000.
42. Burk DR, Senechal-Willis P, Lopez LC, Hogue BG and Daskalova SM: Suppression of lipopolysaccharide-induced inflammatory responses in RAW 264.7 murine macrophages by aqueous extract of Clinopodium vulgare L. (Lamiaceae). J Ethnopharmacol 126: 397-405, 2009.

43. Liu H, Bargouti M, Zughaier S, Zheng Z, Liu Y, Sangadala S, Boden SD and Titus L: Osteoinductive LIM mineralization protein-1 suppresses activation of NF-kappaB and selectively regulates MAPK pathways in pre-osteoclasts. Bone 46: 1328-1335, 2010.

44. Shan J, Fu J, Zhao Z, Kong X, Huang H, Luo L and Yin Z: Chlorogenic acid inhibits lipopolysaccharide-induced cyclooxygenase-2 expression in RAW264.7 cells through suppressing NF-kappaB and JNK/AP-1 activation. Int Immunopharmacol 9: $1042-1048,2009$

45. Watters JJ, Sommer JA, Pfeiffer ZA, Prabhu U, Guerra AN and Bertics PJ: A differential role for the mitogen-activated protein kinases in lipopolysaccharide signaling: The MEK/ERK pathway is not essential for nitric oxide and interleukin lbeta production. J Biol Chem 277: 9077-9087, 2002.

46. Caivano M: Role of MAP kinase cascades in inducing arginine transporters and nitric oxide synthetase in RAW264 macrophages. FEBS Lett 429: 249-253, 1998.

47. Paul A, Cuenda A, Bryant CE, Murray J, Chilvers ER, Cohen P, Gould GW and Plevin R: Involvement of mitogen-activated protein kinase homologues in the regulation of lipopolysaccharide-mediated induction of cyclo-oxygenase-2 but not nitric oxide synthase in RAW 264.7 macrophages. Cell Signal 11: 491-497, 1999. 